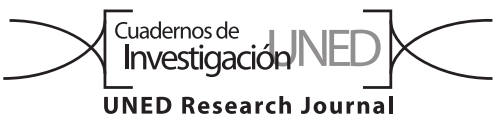

NOTA

\title{
Ataque de Pitangus sulphuratus (Aves: Tyrannidae) a Ciccaba nigrolineata (Aves: Strigidae)
}

\author{
Osvaldo Araya-Céspedes ${ }^{1}$ \& Maggie Hanafin ${ }^{2}$ \\ 1. Universidad Técnica Nacional. Atenas, Costa Rica; woarayac@gmail.com \\ 2. Allegheny College, Pennsylvania, United States of America; maggiehanafin@gmail.com \\ Recibido 04-X-2018 • Corregido 09-I-2019 • Aceptado 30-I-2019
}

ABSTRACT: “A Pitangus sulphuratus (Aves: Tyrannidae) attack on Ciccaba nigrolineata (Aves: Strigidae)". We present a photographic sequence where Ciccaba nigrolineata is attacked by Pitangus sulphuratus in Costa Rica.
RESUMEN: Presentamos una secuencia de fotografías en donde Ciccaba nigrolineata es atacada por Pitangus sulphuratus en Costa Rica.

Palabras clave: aves, búho, tirano, ataque, comportamiento.

Key words: birds, owl, tyrant, attack, behavior.

El búho blanco y negro (Ciccaba nigrolineata) es un gran rapaz que habita en una variedad de bosques tropicales húmedos, incluyendo manglares, bosques de galería y perennifolios (Stiles \& Skutch, 1989; Garrigues \& Dean, 2014; Stearns, 2014).

En general, las presas de los búhos mas grandes incluyen una gran variedad de mamíferos, aves, reptiles, crustáceos y peces, mientras los más pequeños se alimentan de insectos y pequeños vertebrados los cuales pueden ser capturados en horario diurno, nocturno y crepuscular (Stiles \& Skutch, 1989). Por otra parte, en ocasiones tienen que soportar una forma de "acoso". Si un grupo grande de pequeñas aves localiza un búho perchado en su sitio de dormitorio, o en su percha de dormidero, durante el día, estos se congregarán y lo atacarán hasta que el mismo por lo general se desplace a otro árbol, pero rara vez atacará a la bandada que lo está acosando a él (Perrins \& Middleton, 1985).

Describimos acá interacciones entre $C$. nigrolineata y P. sulphuratus, en Colonia Trinidad $\left(10^{\circ} 23^{\prime} 52^{\prime \prime} \mathrm{N}\right.$ \& $\left.84^{\circ} 33^{\prime} 39^{\prime \prime} \mathrm{O}\right)$, Alajuela, Costa Rica, (145msnm). El 30 de abril de 2015, alrededor de las 09:00h, vimos algunas aves acosando a un búho blanco y negro, el cuál se encontraba perchado sobre un árbol cercano a una quebrada. El mismo, tras los ataques constantes se movilizó hacia un área de potreros donde se perchó en un árbol de poró (Erythrina sp.), en el cual fue nuevamente atacado, pero esta vez solo por un individuo de cristofué (Pitangus sulphuratus), el cuál según McNish (2007), es una especie bulliciosa; que acosa a rapaces grandes como en este caso. Los ataques se prolongaron por un tiempo cercano a los 25min en los cuales el búho simplemente evitaba los mismos moviendo su cabeza rápidamente. Sin embargo, en algunas ocasiones el tyrannido lograba dar con el rapaz, tocando su cabeza hasta que el mismo decidió desplazarse a otro sitio.

Consideramos importante este registro acerca del comportamiento entre estas dos especies debido a que el búho blanco y negro es una especie estrictamente nocturna y poco común. Además, en este caso se trata de un individuo en etapa juvenil, para el cual Stiles y Skutch (1989), mencionan que los jóvenes pertenecientes a esta familia abandonan el nido a una edad promedio de 34 días, pero que los mismos seguirán siendo alimentados por sus padres hasta alcanzar mayor edad. Esto nos puede ayudar a comprender de una manera más amplia el comportamiento diurno en esta especie y las interacciones que existen entre ambas especies en donde un individuo que inicia el proceso de abandono del nido puede verse expuesto al ataque de otras aves. 

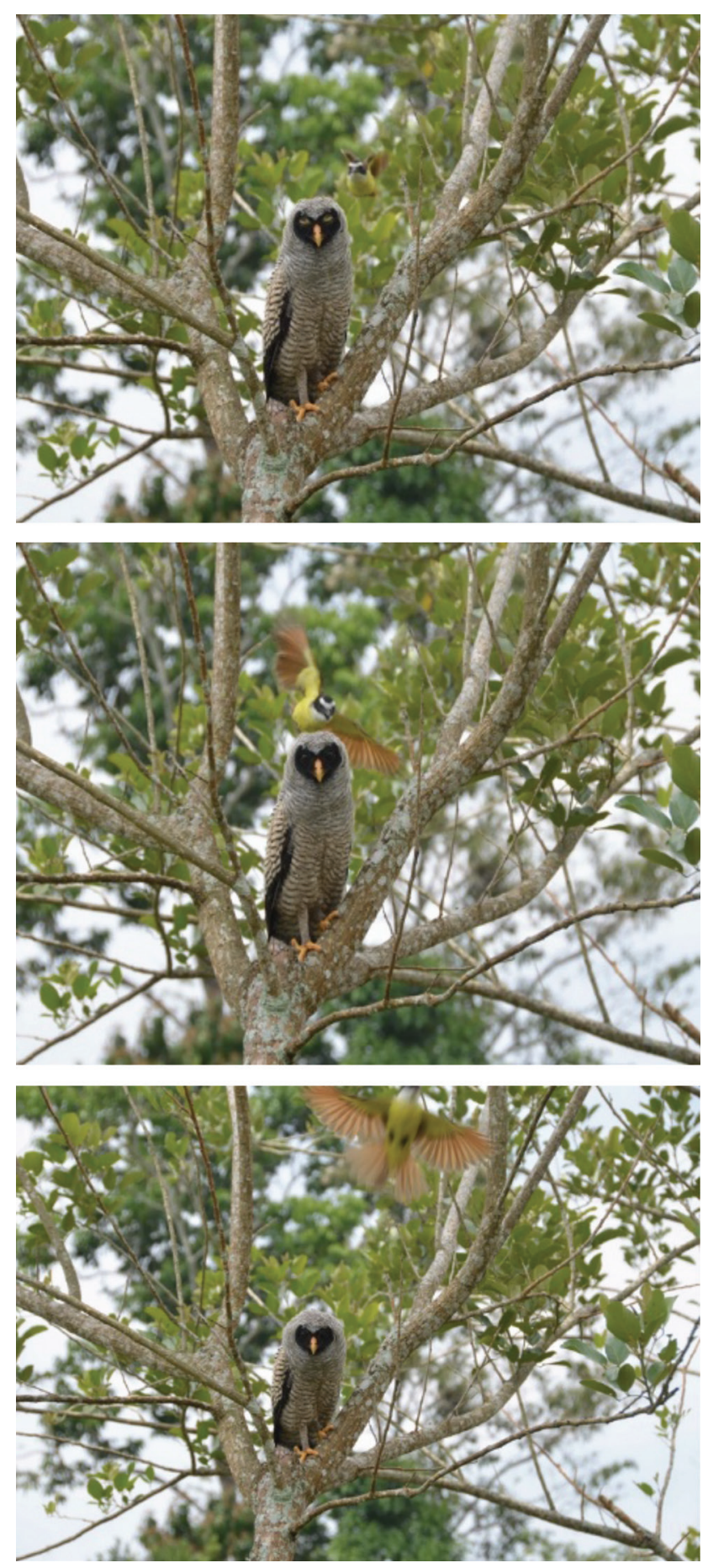

Fig. 1. Ataque de Ciccaba nigrolineata por Pitangus sulphuratus.
Ética, conflicto de intereses y declaración de financiamiento: los autores declaran haber cumplido con todos los requisitos éticos y legales pertinentes, tanto durante el estudio como en el manuscrito; que no hay conflictos de interés de ningún tipo, y que todas las fuentes financieras se detallan plena y claramente en la sección de agradecimientos. Asimismo, están de acuerdo con la versión editada final del documento. El respectivo documento legal firmado se encuentra en los archivos de la revista.

\section{REFERENCIAS}

Garrigues, R., \& Dean, R. (2014). The birds of Costa Rica. Ithaca, United States: Cornell University Press.

McNish, T. (2007). Las aves de los Llanos de la Orinoquia. Bogotá, Colombia: M\&B Producciones y Servicios Ltda.

Perrins, C., \& Middleton, A. (1985). Owl in Encyclopedia of Birds. New York: Facts on File Publications.

Stearns, A. (2014). Black and White Owl (Ciccaba nigrolineata). Recuperado de http://neotropical.birds.cornell. edu/portal/species/overview?p_p_spp $=213336$. DOI: 10.2173/nb.bawowl1.01

Stiles, G., \& Skutch, A. (1989). A Guide to the Birds of Costa Rica. Ithaca, United States: Cornell University Press. 